\title{
Dividend Predictability Around the World
}

\author{
Jesper Rangvid, Maik Schmeling, and Andreas Schrimpf*
}

\begin{abstract}
We show that dividend-growth predictability by the dividend yield is the rule rather than the exception in global equity markets. Dividend predictability is weaker, however, in large and developed markets where dividends are smoothed more, the typical firm is large, and volatility is lower. Our findings suggest that the apparent lack of dividend predictability in the United States does not uniformly extend to other countries. Rather, cross-country patterns in dividend predictability are driven by differences in firm characteristics and the extent to which dividends are smoothed.
\end{abstract}

\section{Introduction}

A fundamental question in asset pricing is whether stock prices move because of news to expected returns or news to expected dividend growth. For the aggregate U.S. stock market, a large literature reports that news to discount rates (i.e., expected future returns) account for the major fraction of variation in dividend yields. ${ }^{1}$ This generally is inferred from the results of predictive regressions,

*Rangvid, jr.fi@cbs.dk, Department of Finance, Copenhagen Business School, Solbjerg Plads 3, DK-2000 Frederiksberg, Denmark; Schmeling, maik.schmeling.1@city.ac.uk, Faculty of Finance, Cass Business School, City University London, 106 Bunhill Row, London EC1Y 8TZ, United Kingdom; and Schrimpf, andreas.schrimpf@bis.org, Bank for International Settlements (BIS), Centralbahnplatz 2, CH-4002 Basel, Switzerland and Center for Research in Econometric Analysis of Time Series (CREATES). We thank Long Chen (the referee), Joshua Coval, Zhi Da, Magnus Dahlquist, Tom Engsted, Jack Favilukis, Ralph Koijen, Jochen Lawrenz, Paul Malatesta (the editor), Lasse Pedersen, Tatjana Puhan, Christian Upper, Jules van Binsbergen, Alexander Wagner, and participants at the 2009 Center for Economic Policy Research (CEPR) European Summer Symposium in Financial Markets, the 2010 European Economic Association (EEA) annual meeting, the 2010 German Finance Association (DGF) annual meeting, the 2010 Verein für Socialpolitik (VfS) annual meeting, the 2011 European Finance Association (EFA) meeting, and seminars at Copenhagen Business School, the IE Business School, CREATES, and Rotterdam University for helpful comments. Schmeling gratefully acknowledges financial support by the German Research Foundation (DFG), and Schrimpf gratefully acknowledges support from the Danish Social Science Research Council as well as from CREATES funded by the Danish National Research Foundation when the paper was written. The paper was previously circulated under the title "Cash-Flow Predictability: Still Going Strong." The views expressed in this paper are those of the authors and do not necessarily reflect those of the Bank for International Settlements.

${ }^{1}$ See, for example, Campbell and Shiller (1988a), (1988b), Campbell (1991), Cochrane (1991), (1992), (2008), Campbell and Ammer (1993), Lettau and Ludvigson (2005), Ang and Bekaert (2007), Ang (2002), Goyal and Welch (2003), Lewellen (2004), Campbell and Thompson (2008), and Larrain and Yogo (2008). 
which suggest that the dividend yield predicts future returns and not dividend growth (e.g., Cochrane (2008), (2011)). However, recent work has shown that this finding does not mean that aggregate U.S. dividend-growth rates cannot be predicted at all. For instance, Lettau and Ludvigson (2005) find that U.S. dividendgrowth rates are predictable by an estimated consumption-dividends-labor income ratio, but not by the dividend yield itself. Chen (2009) demonstrates that the dividend yield did in fact predict aggregate U.S. dividend growth in early periods of industrialization but that the relationship reversed over the post-WWII period. Koijen and Van Binsbergen (2010) show that U.S. marketwide dividends are predictable by the whole history of dividend yields in a present-value model.

We provide fresh evidence on this discussion. Instead of looking solely at U.S. data, we study dividend predictability by the dividend yield in an international setting. This allows us to extend and broaden the evidence on dividend predictability and to explore new hypotheses regarding its underlying economic drivers.

We provide three new findings. First, we systematically evaluate whether the traditional finding from U.S. data, that marketwide dividends are not predictable by the dividend yield on its own, also holds internationally. We find that it does not. This finding is important because it affects how we understand price movements. As Cochrane (2011) points out, evidence based on post-WWII U.S. data suggests that asset prices move because of variation in expected returns only and that movements in expected dividends do not matter. We find that this result does not uniformly extend to other countries.

Our findings suggest that expected dividends do move asset prices in many countries around the world. Indeed, using a global sample of 50 stock markets over the period from 1973 to 2009, we show that marketwide dividends are highly predictable by the dividend yield in smaller and medium-sized equity markets, but generally not in large markets such as the United States. To show this, we first run, country-by-country, traditional predictive regressions of next-year dividendgrowth rates or returns on current dividend yield. We find that in large markets, such as the United States, dividend yields are insignificantly related to future dividend-growth rates, whereas in smaller markets, dividend yields are strongly and significantly related to future dividend-growth rates with $R^{2} \mathrm{~s}$ at times even exceeding $30 \%$. Basically, our finding is that dividend-growth predictability by the dividend yield is the rule rather than the exception in international equity markets. Next, we form two aggregate global stock portfolios, an equal-weighted (EW) and a value-weighted (VW) portfolio, of the market indices of the 50 countries in our sample. For each of these two portfolios, we run predictive regressions of their future dividend-growth rates on current-period dividend yields. We find that dividend growth is highly predictable in the EW portfolio but not predictable at all in the VW portfolio. Since the EW portfolio puts more weight on smaller markets than the VW portfolio by construction, the observed dividend-growth predictability in the EW portfolio arises because dividend growth is significantly more predictable in countries with medium-sized or smaller equity markets compared to countries with large market capitalization, such as the United States.

After having documented that dividends are more predictable in countries with smaller equity markets, we turn to possible explanations for this finding. We first 
investigate the relation between dividend smoothing and dividend predictability. Chen, Da, and Priestley (2012) find that dividend smoothing reduces dividend predictability, because dividend smoothing disconnects dividend payments from fluctuations in dividend yields. Based on this argument and documenting the fact that U.S. firms smooth dividends more today compared to several decades ago, Chen et al. offer an explanation for the finding of Chen (2009) that dividend growth was more predictable by the dividend yield in pre-WWII data. If this is a valid explanation, one may expect to find a link between differences in dividend smoothing across countries and the extent to which dividends are predictable by the dividend yield. To verify this conjecture empirically, we show that dividends are indeed more smoothed in large equity markets, which feature less dividend predictability. Estimating a version of the Lintner (1956) partial-adjustment model, we find that the estimated smoothing parameter is significantly higher in the VW portfolio and even insignificant in the EW portfolio. We also show that dividends react less to changes in earnings in the VW portfolio compared to the EW portfolio. Both of these findings confirm that dividends in large equity markets are smoothed more. Finally, we relate smoothing to predictability and find that in those countries where dividends are smoothed less, dividend predictability by the dividend yield is stronger.

Our third contribution is to examine the underlying factors driving these results and to link dividend predictability to differences in firm characteristics across countries. Our hypotheses are motivated by two recent findings (both using U.S. data). First, Vuolteenaho (2002) shows that dividends are highly predictable when looking at U.S. firm-level data and that firm-level dividend predictability varies with firm size, but aggregate marketwide dividends are unpredictable because cash-flow predictability at the firm level is idiosyncratic and washes out in the aggregate. Second, Leary and Michaely (2011) find that large and mature U.S. firms and firms with stable cash-flow and return processes have a higher tendency to smooth dividends. Based on these findings, a natural hypothesis in our global investigation is that aggregate dividends are more difficult to predict by the dividend yield in countries where the typical firm is large and/or has less volatile dividends and equity returns. To analyze the relation between firm size and dividend predictability, we run panel time-series regressions where we interact the dividend yield of the country with the size of the typical firm in the country, measured for instance by average market capitalization. We find strong evidence that dividend growth is less predictable in countries where the typical firm is large. We next investigate the relation between idiosyncratic volatility (of dividends and returns) and dividend predictability. We find that countries with more stable (i.e., less volatile) returns and dividends feature less predictability of dividend growth by the dividend yield. Thus, cross-country patterns in dividend predictability by the dividend yield are related to differences in firm characteristics across countries.

Finally, we should mention that a few papers before ours have addressed the international dimension of dividend-growth predictability. For instance, in his survey, Campbell (2003) reports dividend-growth rate predictability for a few developed countries but not for the U.S. equity market. Ang and Bekaert (2007) look at the United States, the United Kingdom, France, and Germany, that is, large equity markets, and conclude that "... the evidence for linear cash-flow predictability by 
the dividend yield is weak and not robust across countries or sample periods" (p. 670). A recent paper by Engsted and Pedersen (2010) investigates long time series for four countries (United States, United Kingdom, Denmark, and Sweden) and shows that dividend yields do not predict dividend-growth rates in the United Kingdom and United States (i.e., large countries), but do so in Denmark and Sweden (i.e., small countries). In relation to Campbell (2003), Ang and Bekaert (2007), and Engsted and Pedersen (2010), we provide evidence for many more countries, which allows us to verify systematic differences in predictability patterns across countries. We also link dividend predictability across the globe to cross-country differences in firm characteristics (e.g., firm size and cash-flow volatility) and dividend smoothing to shed light on the mechanism driving dividend predictability by the dividend yield.

The remainder of the paper is as follows: In Section II, we describe our return and dividend data on international equity markets. Section III contains the main finding of our paper, namely, that dividends are more predictable by the dividend yield in smaller capital markets. We show that dividends are smoothed more in larger equity markets in Section IV. In Section V, we show that predictability is higher in countries where the typical firm is small and return and/or dividend volatility high, and that firm size and volatility are related to dividend smoothing. Section VI describes several robustness checks, and Section VII provides conclusions.

\section{Data}

We analyze a total of 50 countries for which dividend yields, share prices, and total return data are available. ${ }^{2}$ This sample covers the 32 industrialized countries, as defined by the International Monetary Fund (IMF), and 18 additional developing countries. We employ a quarterly frequency and the total sample period runs from the first quarter of 1973 to the first quarter of 2009. Data for some countries are available for the total sample period, whereas other countries enter the sample at later points in time. We present the results from a host of robustness checks later in the paper, which verify that our main results are not affected by certain kinds of countries being in the data set throughout the whole sample period (mainly "advanced" markets) and others not (mainly "emerging" markets).

We use the share price indices and total return indices from Morgan Stanley Capital International (MSCI) and dividends and dividend yields from Datastream, as the available MSCI data span a shorter subperiod. All our results reported below are nearly unchanged when we also use returns from Datastream, so that our results are not driven by combining the two data sources. The advantage of using

\footnotetext{
${ }^{2}$ The countries are Argentina, Australia, Austria, Belgium, Brazil, Bulgaria, Canada, Chile, China, Colombia, Czech Republic, Denmark, Finland, France, Germany, Greece, Hong Kong, Hungary, India, Indonesia, Ireland, Israel, Italy, Japan, Luxembourg, Malaysia, Mexico, Netherlands, New Zealand, Norway, Pakistan, Peru, Philippines, Poland, Portugal, Romania, Russia, Singapore, Slovenia, South Africa, South Korea, Spain, Sri Lanka, Sweden, Switzerland, Taiwan, Thailand, Turkey, the United Kingdom, and the United States.
} 
the Datastream data is that we do not have to back out dividends from time series of total returns and price returns. ${ }^{3}$

The dividend yield in a specific equity market is calculated as the total amount of dividends paid out by constituents of that country's equity market index as a percentage of the total market value of the constituents, that is, as $\mathrm{DY}_{t}=100 \times \sum_{n} D_{t} N_{t} / \sum_{n} P_{t} N_{t}$, where DY $=$ aggregate dividend yield on day $t$, $D_{t}=$ dividends per share on day $t, P_{t}=$ unadjusted share price on day $t, n$ indexes constituents, and $N_{t}=$ number of constituents of the index. The dividend yield is thus an average of the individual dividend yields of the constituents weighted by market value, where yields are calculated with trailing dividends over the last 4 quarters.

Descriptive statistics for total returns, dividend growth, the average dividend yield, and information on data availability for the individual countries are reported in Panel A of Table 1. There are large differences in the average dividendgrowth rates across countries. For instance, among those countries for which we have full-sample information, we find the highest average (annual) dividendgrowth rates in countries such as Denmark (10.11\%), Belgium (9.87\%), and Hong Kong $(11.33 \%)$, whereas the lowest average dividend-growth rates are found in Germany (5.66\%), Japan (3.36\%), and the United States (6.19\%). For the countries that enter the sample at later points in time, there are very large spreads in the average dividend-growth rates, ranging from as high as $62.82 \%$ for Russia to as low as $-29.94 \%$ for Bulgaria (however, for Bulgaria, the sample is very short, too). ${ }^{4}$

For our empirical analysis in Section III.B, we form two kinds of aggregate portfolios from our individual-country data: a VW global portfolio and an EW global portfolio. We use each market's capitalization (at the end of the previous quarter) as a fraction of total world-market capitalization (at the end of the previous quarter) as a weight in the VW portfolio. In other words, in the VW portfolio, we use dynamic weights, such that a market that grows in size relative to another market will also be given a larger weight. The VW portfolio is highly dominated by large countries such as the United States (roughly $40 \%$ market share on average), Japan (about 20\%), and the United Kingdom (roughly 10\%), implying that results for the VW portfolio should be expected to closely resemble results from the earlier literature (see, e.g., Ang and Bekaert (2007), who, as mentioned, find no clear evidence for linear cash-flow predictability in these countries). Results for the EW portfolio, on the other hand, more closely resemble the behavior of the bulk of smaller and medium-sized markets: In the EW portfolio, the share given to the United States is only $1 / 15=6.67 \%$ in the beginning of the sample period (we have data for 15 countries in 1973) versus $1 / 50=2 \%$ at the end of the sample period. Descriptive statistics are reported in of Panel B Table 1. We see

\footnotetext{
${ }^{3}$ See, for example, Chen (2009) or Koijen and Van Binsbergen (2010) for the impact of assumptions about dividend reinvestments that are paid out throughout the year.

${ }^{4}$ We checked whether excluding countries for which we have less than 15 years of data (Brazil, Bulgaria, Czech Republic, Hungary, Korea, Romania, Russia, and Slovenia) changes our main findings (see Section VI). We find that excluding these countries does not qualitatively affect the results reported below.
} 
TABLE 1

Descriptive Statistics

Table 1 shows descriptive statistics for all 50 countries in our sample (Panel A) and for an EW as well as a VW portfolio of these countries (Panel B). The second column shows the date of the first observation in our sample; the next six columns show the means and standard deviations of annualized (log) returns (total returns), (log) dividend growth, and dividend yield. The final column reports the number of available quarterly observations.

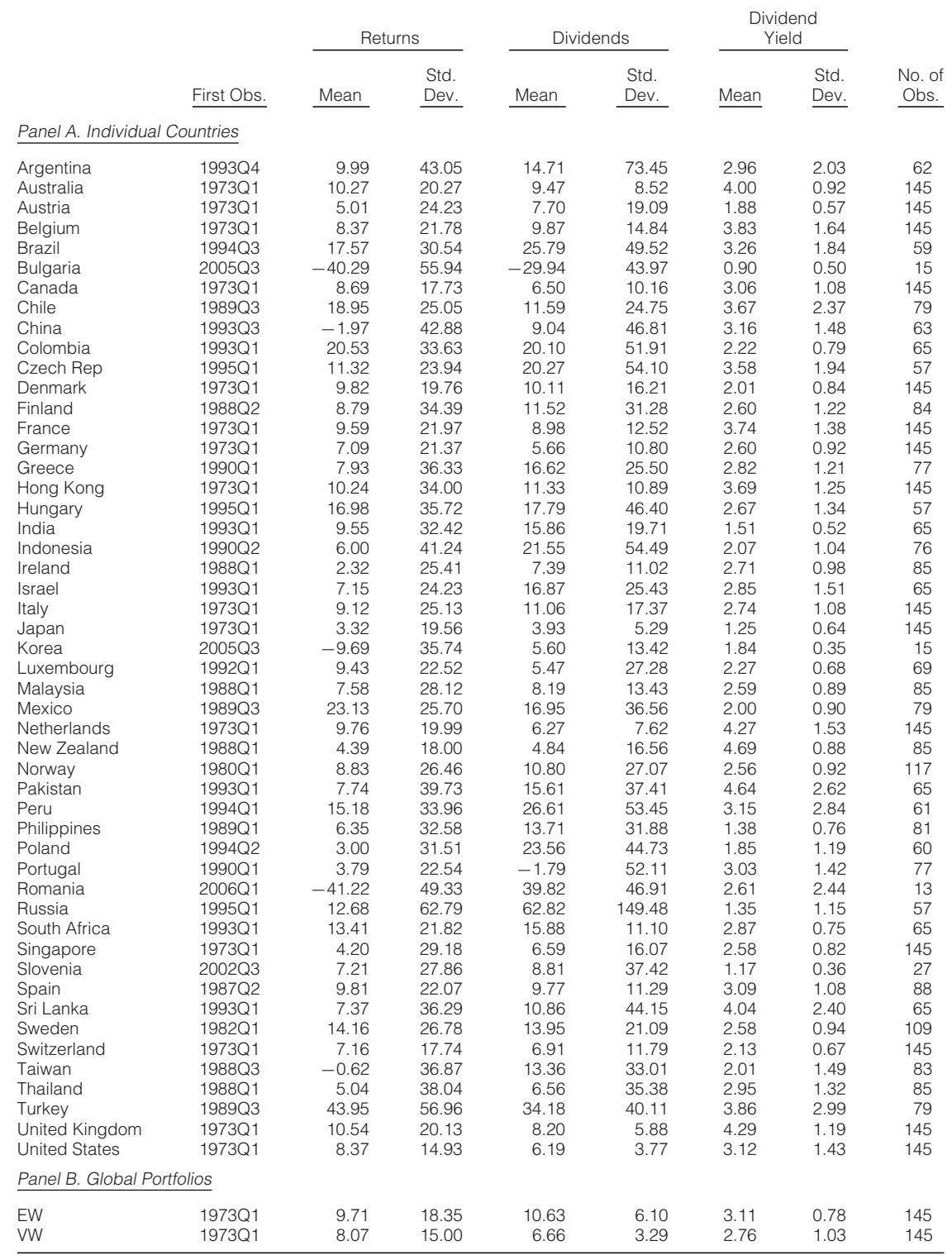

that the EW portfolio has a higher standard deviation for returns and dividend growth, and a higher dividend yield on average when compared to the VW portfolio. 


\section{Dividend Predictability in Global Equity Markets}

Our main interest is the investigation of the drivers of fluctuations in equity valuations in global capital markets. As is well known, Campbell and Shiller (1988a), (1988b) derive a "dynamic Gordon formula" by log-linearizing the definition of returns:

$$
d_{t}-p_{t} \simeq \text { constant }+\mathrm{E}_{t}\left[\sum_{j=1}^{\infty} \rho^{j-1}\left(r_{t+j}-\Delta d_{t+j}\right)\right],
$$

where $d$ is the log of dividends, $p_{t}$ the log of the stock price, $r$ the return, and $\Delta d$ dividend growth. Equation (1) shows that an increase in the dividend yield must imply that investors have lowered their expectations about the future growth rates of dividends and/or have raised their expectations about future returns (i.e., risk premia). Which of the two channels (time variation of expected dividend growth or risk premia) drives equity market valuations is crucial for our theoretical understanding of stock markets. ${ }^{5}$ The remainder of the paper explores empirically which of these two drivers dominates in international equity markets and what the underlying economic drivers are.

\section{A. Predictive Regressions for Individual Countries}

We first test, country-by-country, the implications of equation (1), that is, whether the dividend yield for a specific country forecasts high returns and/or low dividend growth in that country. We run two time-series regressions of future values of dividend-growth rates on current dividend yields and future values of stock returns on current dividend yields:

$$
\begin{aligned}
\Delta d_{i, t+4} & =\alpha_{i, d}+\beta_{i, d}\left(d_{i, t}-p_{i, t}\right)+\varepsilon_{i, t+4}, \\
r_{i, t+4} & =\alpha_{i, r}+\beta_{i, r}\left(d_{i, t}-p_{i, t}\right)+\varepsilon_{i, t+4},
\end{aligned}
$$

where $t$ indexes time and $i$ refers to individual countries. In order to avoid potential seasonality issues with the dividend-growth series, we generally work with an annual (i.e., 4 quarters, forecast horizon). ${ }^{6}$

In our regressions, we base our statistical inference about the regressions' slope coefficients on Newey and West (1987) heteroskedasticity and autocorrelation consistent (HAC) standard errors; Hodrick (1992) standard errors, which were found to be more reliable and accurate by Ang and Bekaert (2007); and a moving-block bootstrap to account for potential finite-sample biases (Stambaugh (1999)) and moving average structure of regression errors due to overlapping observations. ${ }^{7}$

\footnotetext{
${ }^{5}$ Consider, for instance, the two leading paradigms for modeling equity markets: the habit formation model by Campbell and Cochrane (1999) and the long-run risk model by Bansal and Yaron (2004). While the first paper focuses entirely on time variation in risk premia, the latter paper also assigns an important role to changing cash-flow expectations.

${ }^{6}$ We also checked our results for shorter forecast horizons of 1,2 , and 3 quarters. In these (unreported) estimations, we found very similar predictability results as for the annual forecast horizon reported below. We do not report these results to rule out any seasonality issues.

${ }^{7}$ We first block bootstrap returns and dividend yields for each country. We generate 5,000 bootstrap samples and estimate our regressions on these artificial data. This procedure yields the bootstrap
} 
Cochrane (2008) points out that the coefficients from the predictive regressions in equations (2) and (3) are related via the definition of returns. Assuming that dividend yields follow a first-order autoregressive process $d_{i, t+1}-p_{i, t+1}=$ $\alpha_{i, d p}+\phi_{i}\left(d_{i, t}-p_{i, t}\right)+\varepsilon_{i, t+1}$, Cochrane (2008) shows that the coefficients are related as $\beta_{i, r}=1-\rho_{i} \phi_{i}+\beta_{i, d}$, where $\rho_{i}$ is a linearization constant close to 1 . Dividing by $\left(1-\rho_{i} \phi_{i}\right)$ on both sides, the implied restriction of the long-run coefficients is $1=b_{r}^{\mathrm{LR}}-b_{d}^{\mathrm{LR}}$, where $b_{i, r}^{\mathrm{LR}}=\beta_{i, r} /\left(1-\rho_{i} \phi_{i}\right)$ and $b_{i, d}^{\mathrm{LR}}=\beta_{i, d} /\left(1-\rho_{i} \phi_{i}\right)$. Cochrane (2008) shows that, in the same spirit as a variance decomposition, the long-run coefficient $b_{r}^{\mathrm{LR}}$ measures the fraction of dividend-yield variation due to long-run movements in expected future returns while $b_{d}^{\mathrm{LR}}$ measures the fraction of variation due to long-run movements in expected dividend-growth rates.

In Table 2, we show the results from the regressions for those countries for which we have more than 10 years of quarterly data. The table highlights the estimated coefficients $\left(\beta_{r}\right.$ and $\beta_{d}$ ) that are significant according to Newey and West (1987) standard errors: these coefficients are in bold. ${ }^{8}$ We also show $t$-statistics based on moving-block bootstrapped standard errors, the $R^{2} \mathrm{~s}$ from the regressions, and the long-run coefficients $b_{r}^{\mathrm{LR}}$ and $b_{d}^{\mathrm{LR}}$. Furthermore, we report the share of unexpected return variation due to revisions in expected stock returns $\left(\mathrm{V}\left(\eta_{r}\right)\right)$ and revisions in expected dividends $\left(\mathrm{V}\left(\eta_{d}\right)\right)$ based on the standard decomposition of unexpected stock returns $r_{t+1}-\mathrm{E}_{t}\left[r_{t+1}\right]$ into news about future expected returns $\eta_{r, t+1}$ and news about future expected dividends $\eta_{d, t+1}$ from Campbell (1991):

$$
\begin{aligned}
& \eta_{r, t+1}=\mathrm{E}_{t+1}\left[\sum_{j=1}^{\infty} \rho^{j} r_{t+1+j}\right]-\mathrm{E}_{t}\left[\sum_{j=1}^{\infty} \rho^{j} r_{t+1+j}\right], \\
& \eta_{d, t+1}=\mathrm{E}_{t+1}\left[\sum_{j=1}^{\infty} \rho^{j} \Delta d_{t+1+j}\right]-\mathrm{E}_{t}\left[\sum_{j=1}^{\infty} \rho^{j} \Delta d_{t+1+j}\right] .
\end{aligned}
$$

The results reported in Table 2 show that predictability of dividend growth by the dividend yield is a ubiquitous phenomenon in international equity markets. To explain the results in detail, consider first a relatively small market, such as the first country in the table, Argentina. The predictive coefficient $\beta_{d}$ from the dividend-growth regression is large in absolute terms, highly significant using both Newey-West (1987) and block-bootstrapped $t$-statistics, and of the negative sign a priori expected from the Campbell-Shiller (1988a), (1988b) decomposition. The $R^{2}$ of the predictive regression is large and around $34 \%$. Almost all variation in the dividend yield can be accounted for by long-run movements in expected dividend-growth rates, as measured by the estimated $b_{d}^{\mathrm{LR}}$ coefficient. In other

distribution of the estimated coefficients $\beta_{r}, \beta_{d}$ from which we estimate the bootstrap standard error for each predictive coefficient. The $t$-statistic reported in the tables $t^{\mathrm{BS}}$ is based on these bootstrapped standard errors. We increase the block length to $3 h$ (where $h$ is the forecast horizon) in our tests below which partly look at longer forecast horizons, so that longer blocks are chosen for longer forecast horizons to account for the larger degree of serial correlation in overlapping returns at longer forecast horizons.

${ }^{8}$ We have multiplied the estimated coefficients by 100 for ease of readability. 
TABLE 2

Predictive Regressions for Individual Countries

Table 2 shows results for predictive regressions of dividend growth (left panel) and total returns (right panel) on the log dividend yield for each individual country in our sample that has at least 10 years of data. The forecast horizon is 4 quarters. A predictive coefficient $\left(\beta_{d}, \beta_{r}\right)$ is highlighted in bold when the absolute $t$-statistic (Newey-West (1987) HAC) indicates significance at the $5 \%$ level or better. ${ }^{B S}$ shows the $t$-statistic based on a moving-block bootstrap with 5,000 repetitions. The $b^{\mathrm{LR}}$ coefficients are long-run predictive coefficients and measure variance shares (based on a vector autoregressive model with lag length equal to 1 (VAR(1)) of dividend growth, total returns, and the log dividend yield, as in Cochrane (2008)). $\mathrm{V}\left(\eta_{d}\right)$ and $\mathrm{V}\left(\eta_{r}\right)$ denote the share of unexpected return variation attributable to news about future dividends and discount rates, respectively.

\begin{tabular}{|c|c|c|c|c|c|c|c|c|c|c|}
\hline \multirow[b]{2}{*}{ Country } & \multicolumn{5}{|c|}{ Dividend Growth } & \multicolumn{5}{|c|}{ Total Returns } \\
\hline & $\beta_{d}$ & $t^{\mathrm{BS}}$ & $R^{2}$ & $\underline{b_{d}^{\mathrm{LR}}}$ & $\underline{\mathrm{V}\left(\eta_{d}\right)}$ & $\beta_{r}$ & $t^{\mathrm{BS}}$ & $R^{2}$ & $b_{r}^{\mathrm{LR}}$ & $\mathrm{V}\left(\eta_{r}\right)$ \\
\hline Argentina & -56.75 & -3.59 & 0.34 & 1.22 & 1.23 & -8.42 & -0.47 & 0.05 & -0.22 & -0.23 \\
\hline Australia & -18.96 & -2.08 & 0.13 & 0.34 & 0.60 & 39.56 & 3.52 & 0.17 & 0.66 & 0.40 \\
\hline Austria & -37.52 & -3.59 & 0.28 & 1.61 & 0.53 & 15.50 & 1.12 & 0.02 & -0.61 & 0.47 \\
\hline Belgium & -11.70 & -2.54 & 0.14 & 0.80 & 0.33 & 13.44 & 1.49 & 0.05 & 0.20 & 0.67 \\
\hline Brazil & -28.18 & -0.98 & 0.20 & 0.78 & 0.82 & 8.94 & 0.60 & 0.08 & 0.22 & 0.18 \\
\hline Canada & -8.60 & -1.40 & 0.09 & 0.66 & 0.72 & 7.39 & 0.86 & 0.02 & 0.34 & 0.28 \\
\hline Chile & -12.72 & -0.44 & 0.04 & 0.15 & 0.94 & 47.29 & 2.27 & 0.52 & 0.85 & 0.06 \\
\hline China & -45.91 & -2.38 & 0.31 & 0.94 & 1.18 & -1.29 & -0.04 & 0.00 & 0.06 & -0.18 \\
\hline Colombia & -62.55 & -2.01 & 0.22 & 0.51 & 0.79 & 38.64 & 1.80 & 0.12 & 0.49 & 0.21 \\
\hline Czech Rep & -29.55 & -1.58 & 0.13 & 0.83 & 0.18 & 24.40 & 2.49 & 0.24 & 0.17 & 0.82 \\
\hline Denmark & -10.58 & -1.37 & 0.07 & 0.54 & 0.42 & 18.42 & 1.50 & 0.08 & 0.46 & 0.58 \\
\hline Finland & -47.55 & -3.09 & 0.41 & 0.70 & 0.90 & -0.24 & -0.02 & 0.00 & 0.30 & 0.10 \\
\hline France & -3.20 & -0.60 & 0.01 & 0.31 & 0.27 & 24.79 & 2.12 & 0.12 & 0.69 & 0.73 \\
\hline Germany & -13.34 & -3.22 & 0.18 & 0.85 & 0.62 & 9.18 & 0.78 & 0.02 & 0.15 & 0.38 \\
\hline Greece & -26.54 & -2.75 & 0.33 & 0.81 & 0.74 & 22.92 & 1.66 & 0.10 & 0.19 & 0.26 \\
\hline Hong Kong & -10.97 & -1.51 & 0.08 & 0.21 & 0.23 & 60.58 & 4.75 & 0.33 & 0.79 & 0.77 \\
\hline Hungary & -21.15 & -1.27 & 0.07 & 0.57 & 0.73 & 47.04 & 1.92 & 0.20 & 0.43 & 0.27 \\
\hline India & -8.23 & -0.56 & 0.02 & 0.26 & 0.81 & 36.31 & 1.63 & 0.20 & 0.74 & 0.19 \\
\hline Indonesia & -46.04 & -1.86 & 0.44 & 0.39 & 0.00 & 32.75 & 2.42 & 0.36 & 0.61 & 1.00 \\
\hline Ireland & -0.08 & -0.02 & 0.00 & 0.66 & 0.02 & 36.43 & 2.79 & 0.13 & 0.34 & 0.98 \\
\hline Israel & -22.04 & -1.35 & 0.19 & 1.18 & 0.89 & 0.07 & 0.00 & 0.00 & -0.18 & 0.11 \\
\hline Italy & -20.70 & -2.73 & 0.15 & 0.85 & 1.05 & 12.79 & 1.24 & 0.02 & 0.15 & -0.05 \\
\hline Japan & 1.53 & 0.82 & 0.01 & -0.28 & 0.33 & 11.14 & 1.36 & 0.06 & 1.28 & 0.67 \\
\hline Malaysia & -8.77 & -1.20 & 0.07 & 0.20 & 0.01 & 43.16 & 2.49 & 0.21 & 0.80 & 0.99 \\
\hline Mexico & -16.32 & -1.26 & 0.04 & 0.53 & 0.30 & 35.53 & 2.76 & 0.24 & 0.47 & 0.70 \\
\hline Netherlands & -5.52 & -2.02 & 0.08 & 0.43 & 0.22 & 14.58 & 1.56 & 0.07 & 0.57 & 0.78 \\
\hline New Zealand & -69.53 & -5.43 & 0.48 & 1.01 & 0.78 & -0.83 & -0.06 & 0.00 & -0.01 & 0.22 \\
\hline Norway & -19.06 & -1.54 & 0.08 & 0.60 & 0.33 & 28.74 & 2.65 & 0.12 & 0.40 & 0.67 \\
\hline Pakistan & -13.99 & -0.76 & 0.06 & 0.53 & 0.18 & 23.43 & 1.30 & 0.14 & 0.47 & 0.82 \\
\hline Peru & -30.41 & -1.46 & 0.25 & 0.90 & 0.63 & 7.31 & 0.93 & 0.04 & 0.10 & 0.37 \\
\hline Philippines & -25.12 & -1.65 & 0.15 & 0.88 & 0.16 & 14.01 & 0.88 & 0.04 & 0.12 & 0.84 \\
\hline Poland & -33.43 & -1.37 & 0.17 & 0.94 & -0.35 & 10.43 & 0.74 & 0.05 & 0.06 & 1.35 \\
\hline Portugal & -70.28 & -4.86 & 0.53 & 1.00 & 0.67 & 13.64 & 0.79 & 0.03 & 0.00 & 0.33 \\
\hline Russia & -109.81 & -3.98 & 0.62 & 0.84 & 0.84 & -4.54 & -0.21 & 0.01 & 0.16 & 0.16 \\
\hline South Africa & -6.85 & -1.38 & 0.05 & 0.54 & 0.60 & 17.03 & 0.71 & 0.04 & 0.46 & 0.40 \\
\hline Singapore & -6.22 & -0.94 & 0.02 & 0.34 & 0.26 & 39.25 & 3.47 & 0.18 & 0.66 & 0.74 \\
\hline Spain & -3.46 & -0.31 & 0.01 & 0.38 & 0.23 & 19.50 & 1.23 & 0.07 & 0.62 & 0.77 \\
\hline Sri Lanka & -39.24 & -1.77 & 0.27 & 1.50 & 1.12 & 4.37 & 0.25 & 0.00 & -0.50 & -0.12 \\
\hline Sweden & -23.52 & -1.43 & 0.14 & 0.63 & 0.84 & 42.63 & 2.38 & 0.16 & 0.37 & 0.16 \\
\hline Switzerland & -15.79 & -3.35 & 0.20 & 0.96 & 0.71 & 2.81 & 0.30 & 0.00 & 0.04 & 0.29 \\
\hline Taiwan & -15.35 & -1.15 & 0.11 & 0.84 & 0.72 & 12.18 & 0.84 & 0.04 & 0.16 & 0.28 \\
\hline Thailand & -22.07 & -2.01 & 0.08 & 0.41 & 1.11 & 24.29 & 2.29 & 0.12 & 0.59 & -0.11 \\
\hline Turkey & -9.71 & 0.73 & 0.04 & 0.15 & 0.41 & 38.98 & 2.56 & 0.28 & 0.85 & 0.59 \\
\hline United Kingdom & 8.46 & 1.90 & 0.07 & -0.12 & -0.25 & 37.79 & 3.98 & 0.28 & 1.12 & 1.25 \\
\hline United States & 2.22 & 1.03 & 0.06 & -0.24 & -0.11 & 10.23 & 1.76 & 0.09 & 1.24 & 1.11 \\
\hline
\end{tabular}

words, dividend growth is highly predictable by the dividend yield in Argentina, and changing expectations about dividend growth account for the largest fraction of dividend-yield variation. Consider then the results from the return predictability regression. In Argentina, returns are not significantly related to fluctuations in dividend yields. The estimate of $\beta_{r}$ is insignificant, the $R^{2}$ is low, and the longrun coefficient $b_{r}^{\mathrm{LR}}$ is low, too. All in all, dividend growth is highly predictable by the dividend yield in Argentina, whereas returns are not.

Results for other smaller and medium-sized markets are generally similar. As one further example, consider another small country for which full-sample 
information is available, the third country in the table, Austria. The conclusion for Austria is exactly the same as that for Argentina: Dividend growth is highly predictable by the dividend yield, whereas returns are not predictable. The broad picture of Table 2 allows for the conclusion that in global equity markets, the largest fraction of the variation in dividend yields can be accounted for by changes in expectations about future dividend growth rather than changes in expected returns. In fact, only in 15 markets out of the 50 markets studied in this paper do changes in expected returns explain a larger fraction of the variance of dividend yields (i.e., does the estimated $b_{r}^{\mathrm{LR}}$ exceed $b_{d}^{\mathrm{LR}}$ ). In the majority (i.e., 35) of capital markets worldwide, news about future dividends clearly dominates as the main driver of equity market valuations. These results run counter to the general impression in the literature, based on U.S. data, that the dominant driver of equity market valuations is variation of expected returns and not variation of expected future dividend growth (e.g., Cochrane (2008), (2011)).

Interestingly, those countries where dividend-growth rates are not or less predictable are mainly large countries. To illustrate, consider the U.S. capital market, which is in fact the largest market in the sample. Table 2 shows that U.S. dividend-growth rates are not significantly predictable by the dividend yield. The fraction of variation in dividend yields due to changes in expectations about longrun dividend-growth rates is small. On the other hand, returns are predictable by dividend yields (even if only marginally significant using block bootstrap standard errors), and basically all of the variation in the dividend yields is attributable to long-run variation in expected returns. Hence, the results we report here for the United States are like those one is used to seeing in the U.S.-based literature (see, e.g., Cochrane (2008), Chen (2009), taking into account that we have 1973-2009 data at our disposal here).

To provide a more general picture of the relation between the size of the country's equity market and dividend-growth predictability, we show in Figure 1 scatter plots of the relation between the estimated predictive coefficient $\beta_{d}$ and market size (Graph A) and between the long-run coefficients $b_{d}^{\mathrm{LR}}$ and market size (Graph B). Market size is calculated as the U.S. dollar value of the country's aggregate stock market at the end of the sample period. The point we want to make here is that dividend-growth rates are more predictable in smaller markets. If this is true, we should see a positive relation between market size and the size of the predictive coefficients (as the predictive coefficients are negative) in Graph A of Figure 1: The smaller the country in terms of market capitalization, the more negative the predictive coefficient (i.e., the more predictable is dividend growth by the dividend yield). This is indeed what the graph reveals: The correlation between the estimated coefficients and log market capitalization is 0.41 and significant. In other words, Graph A shows that the estimated predictive coefficient tends to be closer to 0 when the market in question is larger. Turning to Graph B, we would expect to see a negative relation between market size and $b_{d}^{\mathrm{LR}}$ if dividend growth is more predictable in smaller markets, as $b_{d}^{\mathrm{LR}}$ measures the fraction of dividend-yield variation due to long-run fluctuations in expected dividend growth. This is what we find. Indeed, we see a negative relation between market size and $b_{d}^{\mathrm{LR}}$ with a correlation coefficient of -0.58 . In other 
FIGURE 1

Dividend Predictability and Market Size

Figure 1 plots log market capitalization of individual countries (horizontal axis) against the predictive coefficient from predictive dividend regressions (Graph A) or long-run predictive coefficients (Graph B) on the vertical axis.

Graph A. Predictive Dividend Coefficient

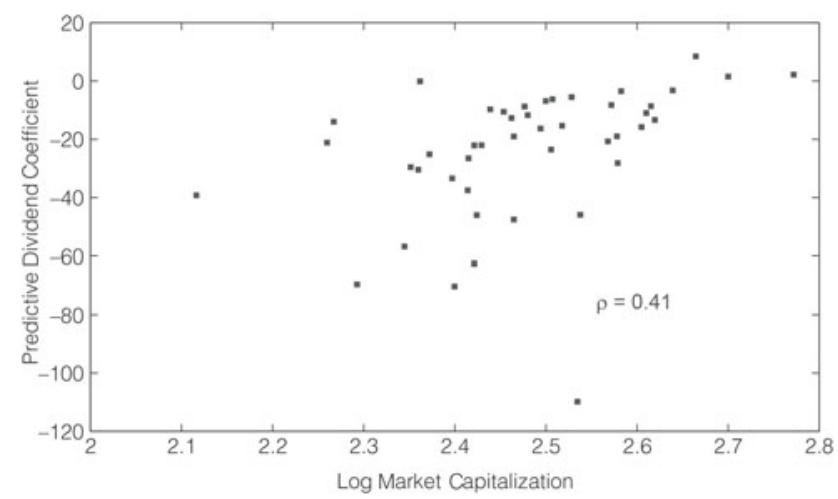

Graph B. Long-Run Predictive Dividend Coefficient

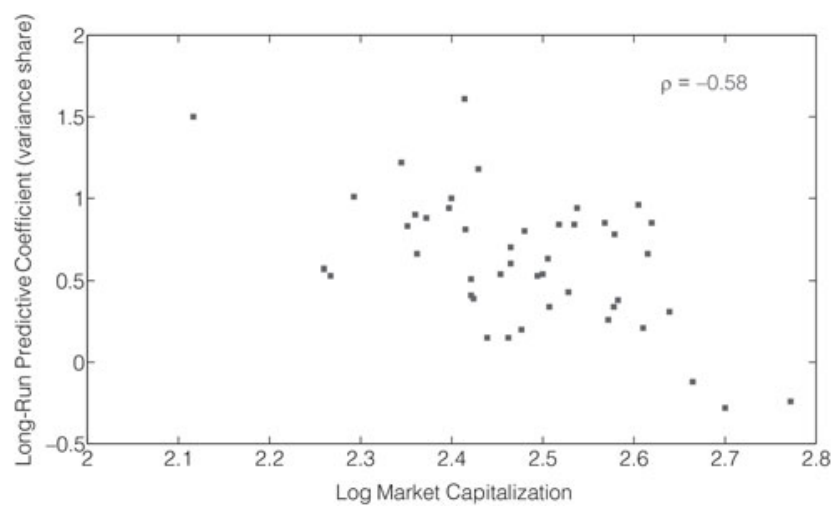

words, the larger the market, the closer to 0 is $b_{d}^{\mathrm{LR}}$. As illustrated by these two graphs in Figure 1, dividend growth is generally highly predictable by the dividend yield in smaller and medium-sized capital markets, but less so in larger equity markets. ${ }^{9}$

\section{B. Predictive Regressions for Global Portfolios}

As our next step, we turn to dividend and return predictability using our EW and VW portfolios described in Section II. The advantage of using the

\footnotetext{
${ }^{9}$ The relation between market capitalization and dividend predictability shown in Figure 1 is not perfect, of course, since the sample period varies across countries and since market capitalization is a crude measure for market development. Nevertheless, it seems clear that there are significant differences in dividend predictability across countries. We provide further tests in Section III.B, which show that the overall pattern identified in Figure 1 is robust.
} 
EW and VW portfolios is that we can make some general statistical judgments about dividend-growth predictability in small and large markets. The regressions we run are as follows:

$$
\begin{aligned}
\Delta d_{t+h} & =\alpha_{d}^{(h)}+\beta_{d}^{(h)}\left(d_{t}-p_{t}\right)+\varepsilon_{t+h}^{(h)}, \\
r_{t+h} & =\alpha_{r}^{(h)}+\beta_{r}^{(h)}\left(d_{t}-p_{t}\right)+\varepsilon_{t+h}^{(h)}
\end{aligned}
$$

that is, compared to equations (2) and (3), there are no subscripts $i$ as we work on the portfolio level including all countries. On the other hand, we now show results for different forecast horizons $h$ (i.e., $h=4,8,12$, and 16 quarters). We also report the share of unexpected returns variation due to changes in expected returns, $\mathrm{V}\left(\eta_{r}\right)$, and dividends, $\mathrm{V}\left(\eta_{d}\right)$, as in Table $2 .^{10}$

The results are reported in Table 3. Consider the annual $(h=4)$ predictive regressions first. The evidence is summarized by

$$
\begin{aligned}
& \mathrm{VW}: \Delta d_{t+4}=\text { constant }+\underset{[0.75]}{1.40}\left(d_{t}-p_{t}\right), \quad \bar{R}^{2}=0.01, \\
& \mathrm{EW}: \Delta d_{t+4}=\text { constant }-\underset{[-3.08]}{12.06}\left(d_{t}-p_{t}\right), \quad \bar{R}^{2}=0.15,
\end{aligned}
$$

where the numbers in square brackets below the coefficient estimates are NeweyWest (1987) HAC-based $t$-statistics. The results are clear-cut: When we use value weights, we cannot reject that the predictive coefficient is 0 and that dividends consequently are unpredictable by the dividend yield. There is clear evidence of dividend-growth predictability, however, in the case of the EW portfolio. The extent to which the dividend yield of the EW portfolio predicts future dividendgrowth rates is noteworthy with an $R^{2}$ of around $15 \%$. By construction, the strong difference between the results using the VW and EW portfolios is due to larger weights given to the smaller markets in the EW portfolio. Hence, confirming the results from the previous subsection, there is significant evidence for cash-flow predictability by the dividend yield. This is not the case for very large markets such as the United States, but for the vast majority of equity markets worldwide, mostly medium-sized and smaller markets.

This conclusion is supported by the variance shares. The share of unexpected return variation due to changes in expected dividends is higher in the $\mathrm{EW}$ portfolio (0.44) compared to the VW portfolio $(0.22)$. We also see that the share due to return variation is higher in the VW portfolio (0.78) compared to its value for the EW portfolio (0.54).

When we increase the horizon over which we measure dividend growth (increase $h$ ), we see from Table 3 that the associated $t$-statistics tend to decline. ${ }^{11}$ Hence, the dividend predictability we document in the EW portfolio is large at

\footnotetext{
${ }^{10}$ These variance shares are obtained from estimating a VAR(1) that is based on an annual frequency to avoid seasonality issues. Thus, the variance shares are reported only for an annual forecast horizon.

${ }^{11}$ In Table 3, we also report $R^{2}$ s implied by a VAR(1) (denoted $R_{\mathrm{IH}}^{2}$ ), as in Hodrick (1992), so that we can compare direct $R^{2}$ s from overlapping horizons with $R^{2} \mathrm{~s}$ implied by regressions based on nonoverlapping observations.
} 
TABLE 3

Predictive Regressions

Table 3 shows estimates of long-horizon predictive regressions

$$
\begin{aligned}
\Delta d_{t+h} & =\alpha_{d}^{(h)}+\beta_{d}^{(h)}\left(d_{t}-p_{t}\right)+\varepsilon_{t+h}^{(h)}, \\
r_{t+h} & =\alpha_{r}^{(h)}+\beta_{r}^{(h)}\left(d_{t}-p_{t}\right)+\varepsilon_{t+h}^{(h)},
\end{aligned}
$$

for two global portfolios, namely, the EW (left part of the table) and VW market portfolios constructed from aggregating all individual sample countries. Numbers in square brackets are $t$-values based on Newey-West (1987) $\left(t^{\mathrm{NW}}\right)$, Hodrick (1992) $\left(t^{H}\right)$, or moving-block bootstrap standard errors $\left(t^{\mathrm{BS}}\right) . \bar{R}^{2}$ denotes the adjusted regression $R$-squared, whereas $R_{\| H}^{2}$ de-

\begin{tabular}{|c|c|c|c|c|c|c|c|c|c|}
\hline \multicolumn{5}{|c|}{ EW } & \multicolumn{5}{|c|}{ VW } \\
\hline$h$ & 4 & 8 & 12 & 16 & $h$ & 4 & 8 & 12 & 16 \\
\hline \multicolumn{10}{|c|}{ Panel A. Dependent Variable: Dividend Growth } \\
\hline$\beta_{d}$ & -12.06 & -20.36 & -18.44 & -19.29 & $\beta_{d}$ & 1.4 & 3.2 & 5.21 & 6.52 \\
\hline $\begin{array}{l}t^{\mathrm{NW}} \\
t^{\mathrm{HS}}\end{array}$ & $\begin{array}{l}{[-3.08]} \\
{[-3.19]} \\
{[-2.61]}\end{array}$ & $\begin{array}{l}{[-2.22]} \\
{[-2.78]} \\
{[-1.92]}\end{array}$ & $\begin{array}{l}{[-1.39]} \\
{[-1.95]} \\
{[-1.25]}\end{array}$ & $\begin{array}{l}{[-1.39]} \\
{[-1.64]} \\
{[-1.24]}\end{array}$ & $\begin{array}{l}t^{\mathrm{NW}} \\
t^{\mathrm{H}} \\
t^{\mathrm{BS}}\end{array}$ & $\begin{array}{l}{[0.75]} \\
{[0.94]} \\
{[0.66]}\end{array}$ & $\begin{array}{l}{[0.79]} \\
{[1.12]} \\
{[0.61]}\end{array}$ & $\begin{array}{l}{[0.90]} \\
{[1.27]} \\
{[0.57]}\end{array}$ & $\begin{array}{l}{[0.96} \\
{[1.23]} \\
{[0.71]}\end{array}$ \\
\hline $\begin{array}{l}\bar{R}^{2} \\
R_{\mathrm{IH}}^{2}\end{array}$ & $\begin{array}{l}0.15 \\
0.27\end{array}$ & $\begin{array}{l}0.17 \\
0.35\end{array}$ & $\begin{array}{l}0.08 \\
0.37\end{array}$ & $\begin{array}{l}0.07 \\
0.37\end{array}$ & $\begin{array}{l}\bar{R}^{2} \\
R_{I \mathrm{H}}^{2}\end{array}$ & $\begin{array}{l}0.01 \\
0.05\end{array}$ & $\begin{array}{l}0.02 \\
0.02\end{array}$ & $\begin{array}{l}0.03 \\
0.02\end{array}$ & $\begin{array}{l}0.03 \\
0.01\end{array}$ \\
\hline $\mathrm{V}\left(\eta_{d}\right)$ & 0.46 & - & - & - & $\mathrm{V}\left(\eta_{d}\right)$ & 0.22 & - & - & - \\
\hline \multicolumn{10}{|c|}{ Panel B. Dependent Variable: Total Returns } \\
\hline$\beta_{r}$ & 21.18 & 31.30 & 38.21 & 54.70 & $\beta_{r}$ & 14.00 & 27.11 & 40.28 & 52.59 \\
\hline $\begin{array}{l}t^{\mathrm{NW}} \\
t^{\mathrm{H}} \\
t^{\mathrm{BS}}\end{array}$ & $\begin{array}{l}{[2.69]} \\
{[2.02]} \\
{[2.25]}\end{array}$ & $\begin{array}{l}{[2.27]} \\
{[1.47]} \\
{[1.52]}\end{array}$ & $\begin{array}{l}{[1.92]} \\
{[1.28]} \\
{[1.29]}\end{array}$ & $\begin{array}{l}{[2.57]} \\
{[1.44]} \\
{[1.69]}\end{array}$ & $\begin{array}{l}t^{\mathrm{NW}} \\
t^{\mathrm{H}} \\
t^{\mathrm{BS}}\end{array}$ & $\begin{array}{l}{[2.49]} \\
{[2.14]} \\
{[2.08]}\end{array}$ & $\begin{array}{l}{[2.37]} \\
{[1.99]} \\
{[1.53]}\end{array}$ & $\begin{array}{l}{[2.65]} \\
{[2.00]} \\
{[1.37]}\end{array}$ & $\begin{array}{l}{[3.26]} \\
{[2.06]} \\
{[1.62]}\end{array}$ \\
\hline $\begin{array}{l}\bar{R}^{2} \\
R_{I \mathrm{H}}^{2}\end{array}$ & $\begin{array}{l}0.06 \\
0.07\end{array}$ & $\begin{array}{l}0.09 \\
0.11\end{array}$ & $\begin{array}{l}0.11 \\
0.14\end{array}$ & $\begin{array}{l}0.20 \\
0.16\end{array}$ & $\begin{array}{l}\bar{R}^{2} \\
R_{I \mathrm{H}}^{2}\end{array}$ & $\begin{array}{l}0.08 \\
0.09\end{array}$ & $\begin{array}{l}0.16 \\
0.16\end{array}$ & $\begin{array}{l}0.23 \\
0.22\end{array}$ & $\begin{array}{l}0.33 \\
0.28\end{array}$ \\
\hline $\mathrm{V}\left(\eta_{r}\right)$ & 0.54 & - & - & - & $\mathrm{V}\left(\eta_{r}\right)$ & 0.78 & - & - & - \\
\hline
\end{tabular}
notes the $R$-squared implied as VAR(1), as in Hodrick (1992).

the shorter horizons and stays large and significant up to 2 years out. Regardless of the horizon, dividend growth is not predictable in the VW portfolio.

It seems interesting that the predictability of dividend growth remains significant after aggregating each individual country into a global portfolio. Chen and Zhao (2009) argue that it does not seem to be a diversification effect that drives out dividend-growth predictability when moving from the firm level to the aggregate level, as reported by Vuolteenaho (2002). We also find that dividend predictability does not wash out in the aggregate: Both indexes we study are highly diversified, but evidence for dividend-growth predictability is strongest when larger markets receive less weight, as in the case of the global EW portfolio.

Annual returns seem to be predictable both in the EW and the VW portfolios. Our findings for the VW portfolio thus reflect the findings in the literature that uses U.S. data: Dividend-growth rates are not predictable by the dividend yield, whereas returns are. When predicting long-horizon returns, the statistical significance of our results depends on the choice of standard errors: The bootstrap standard errors are much larger than the Newey-West (1987) standard errors in the return regressions due to the fact that we are dealing with relatively few observations here such that finite-sample biases (Stambaugh (1999)) become relevant. In fact, long-horizon returns seem to be predictable in both the EW and the VW portfolios when judged via Newey-West or Hodrick (1992) $t$-statistics, 
but predictive coefficients are insignificant when judged via block-bootstrapped $t$-statistics. ${ }^{12}$

All in all, we have shown thus far that dividends are strongly predictable by dividend yields in equity markets worldwide and that predictability is more pronounced in smaller markets. The remainder of the paper explores which economic drivers may account for this result.

\section{Dividend Predictability and Dividend Smoothing}

In this section, we show that dividends are smoother in larger and more mature equity markets. This is important because dividend smoothing makes dividends more difficult to predict by the dividend yield as dividend fluctuations can become disconnected from movements in the dividend yield. ${ }^{13}$ Hence, if dividends by firms are more smoothed in countries with large equity markets, dividends will also be difficult to predict in these markets. To show this, we proceed in two steps. We first show that dividends are indeed smoother in countries with large equity markets. Afterward, we directly explore the relation between dividend smoothing and the strength of dividend-growth predictability.

We use the EW and VW portfolios to show that dividend smoothing is higher in countries with larger market capitalization. Our analysis is based on the Lintner (1956) partial-adjustment model:

$$
\Delta D_{t}=\beta_{0}+\beta_{1} \Delta \mathrm{E}_{t}+\beta_{2} \Delta D_{t-1}+\varepsilon_{t},
$$

where $\Delta D_{t}$ is the annual change in the level of dividends and $\Delta \mathrm{E}_{t}$ the annual change in earnings. In this model, $1-\beta_{2}$ measures the speed of adjustment toward the long-run target dividend payout ratio that Lintner assumed managers partially adjust toward. Hence, $\beta_{2}$ measures the degree of smoothing. ${ }^{14}$ The results are as follows:

$$
\begin{array}{ll}
\text { EW: } & \Delta D_{t}=\underset{[2.40]}{4.25}+\underset{[4.68]}{0.42} \Delta \mathrm{E}_{t}+\underset{[1.56]}{0.19} \Delta D_{t-1}, \quad R^{2}=0.40, \\
\text { VW: } & \Delta D_{t}=\underset{[2.28]}{2.16}+\underset{[4.38]}{0.24} \Delta \mathrm{E}_{t}+\underset{[3.44]}{0.40 \Delta D_{t-1},} \quad R^{2}=0.47,
\end{array}
$$

where the numbers in square brackets below the coefficient estimates are NeweyWest (1987) $t$-statistics. We thus find that the smoothing parameter is significant in the VW portfolio in which larger countries dominate. We also find that we

\footnotetext{
${ }^{12}$ Several authors have noted that the use of Newey-West (1987) standard errors in long-horizon regressions may overstate predictive power, particularly when there is a strong overlap (Ang and Bekaert (2007)).

${ }^{13}$ As mentioned in Section I, Chen et al. (2012) investigate the relation between dividend smoothing and predictability using data on U.S. firms. They show that in the U.S. post-WWII sample, dividends are much smoother (and hence unpredictable) compared to the pre-WWII sample, where U.S. dividend growth was predictable by the dividend yield, as evinced by Chen (2009).

${ }^{14}$ Lintner specified his original model with the explanatory variables in levels (i.e., using $\mathrm{E}_{t}$ and $D_{t-1}$ instead of $\Delta \mathrm{E}_{t}$ and $\left.\Delta D_{t-1}\right)$. As is common nowadays, we use first differences of earnings and dividends to obtain stationary variables.
} 
cannot reject that dividends are not smoothed (the smoothing parameter is not statistically different from 0 ) in the EW portfolio in which smaller countries get a larger weight. Equally interesting, the results show that dividends respond more to earnings in smaller countries, as seen through the larger coefficient to $\Delta \mathrm{E}_{t}$ in the EW portfolio. When earnings increase, dividends comove to a larger extent in the case of the EW portfolio compared to the VW portfolio, suggesting that dividends are smoothed more in larger markets. In fact, a simple test for equality of the $\beta$ coefficients in the two regressions leads us to reject equality of the $\beta_{1} \mathrm{~s}$ with a $p$-value of 0.037 and to marginally reject equality of the $\beta_{2} \mathrm{~s}$ with a $p$-value of 0.082 . This suggests that dividends comove significantly more with earnings and are more smoothed in the EW portfolio compared to the VW portfolio.

An additional way of seeing this is by directly looking at the ratio between volatility of earnings and dividends:

$$
S=\frac{\sigma(\Delta d)}{\sigma(\Delta e)},
$$

where $S$ is defined as the "smoothing parameter," as in Chen et al. (2012). Note that a higher value of $S$ means less smoothing, since dividend growth is more volatile relative to earnings growth for higher values of $S$. If dividends are smooth in relation to earnings, $\sigma(\Delta d)$ is low relative to $\sigma(\Delta e)$ and $S$ is consequently small. We find that $S=0.92$ for the EW portfolio and $S=0.64$ for the VW portfolio, again indicating that dividends are more smoothed in countries with larger equity markets.

Finally, we investigate the direct relation between the extent to which dividends are smoothed and how strongly they are predictable by the dividend yield. To do so, we regress the predictive $R^{2}$ from the individual-country dividendpredictability regressions in Table 2 on the smoothing parameter in a simple crosssectional regression (with White (1980) standard errors); that is, we estimate

$$
R_{\Delta d, i}^{2}=\alpha+\beta S_{i}+\varepsilon_{i}
$$

We obtain an estimate of $\beta$ equal to 0.11 with a $t$-statistic of 2.32 and an $R^{2}$ of $12 \%$; that is, there exists a positive relation between the smoothing parameter and the predictability of dividends across countries: In those countries where there is less smoothing (i.e., high volatility of dividends relative to the volatility of earnings), predictability of dividend growth by the dividend yield is stronger. ${ }^{15}$ These are generally countries with smaller equity markets.

\section{Dividend Predictability and Firm Characteristics}

So far, we have shown that dividends are more predictable in smaller countries and that dividends are less smooth in these countries, too. But what economic mechanism drives these empirical patterns? Dividend policies are the results of

\footnotetext{
${ }^{15}$ We acknowledge that the predictive $R^{2}$ is measured with error. For this reason, we interpret these results with caution.
} 
decisions taken by individual firms, so why are the dividends of firms in smaller countries less smooth and more predictable by the dividend yield? Motivated by the results in Leary and Michaely (2011) that large and mature U.S. firms and U.S. firms with less volatile cash flows tend to smooth dividends more, we investigate two hypotheses in this section: i) whether dividends are more predictable in smaller markets since the typical firm in these countries is smaller (if small firms smooth less, as Leary and Michaely document for the United States, their dividends might be more predictable) and ii) whether dividends are more predictable in smaller markets since the volatility of firms' dividends or returns is higher in smaller equity markets. ${ }^{16}$

\section{A. Firm Size and Dividend Predictability}

We use two measures of firm size in a country to investigate whether differences in firm size (via the link to dividend smoothing) can explain the differences in dividend predictability across countries: the average size of firms in the country and, in order to capture the size of the right tail of the firm-size distribution, the $90 \%$ quantile of the country's firm-size distribution. To calculate the average size of firms in a country, we divide a country's total stock market capitalization (converted to U.S. dollars) by the number of firms in the country. To calculate the $90 \%$ quantile of the country's firm-size distribution, we calculate the $90 \%$ quantile of the cross-sectional firm-size distribution of all available firms' market capitalizations (in U.S. dollars) in a given country in a given quarter. The latter measure is used since it is robust to extreme outliers and better captures the firm size of the top decile of companies in a country. This could be potentially important since large firms usually account for the bulk of dividend payments, at least in the United States (DeAngelo, DeAngelo, and Skinner (2004)). Finally, since market capitalizations grow more or less steadily over time, we deflate both firm-size measures in each quarter by the cross-sectional average (log deviations). Hence, for each country and each quarter, our firm-size proxies capture the percentage deviation from the average value of all countries.

To test whether dividend growth is more predictable in countries where the typical firm is relatively small, we run fixed-effects, unbalanced predictive panel regressions based on all countries and observations. We extend the setup with an interaction term between firm size in country $i, \mathrm{FS}_{i}$ (where $\mathrm{FS}_{i}$ thus represents either the average market capitalization of the firms in the country or the $90 \%$ quantile of the country's firm-size distribution), and the dividend yield in country $i$ :

$$
\begin{aligned}
\Delta d_{i, t+h} & =\alpha_{i, d}^{(h)}+\beta_{d}^{(h)}\left(d_{i, t}-p_{i, t}\right)+\beta_{\mathrm{FS}, d}^{(h)}\left(d_{i, t}-p_{i, t}\right) \mathrm{FS}_{i, t}+\varepsilon_{i, t+h}^{(h)}, \\
r_{i, t+h} & =\alpha_{i, r}^{(h)}+\beta_{r}^{(h)}\left(d_{i, t}-p_{i, t}\right)+\beta_{\mathrm{FS}, r}^{(h)}\left(d_{i, t}-p_{i, t}\right) \mathrm{FS}_{i, t}+\varepsilon_{i, t+h}^{(h)},
\end{aligned}
$$

\footnotetext{
${ }^{16}$ Apart from size and volatility, Leary and Michaely (2011) also find that several other characteristics of firms are related to how strongly they smooth dividends. Inter alia, firms that are younger, more opaque with less analyst coverage and firms with lower levels of institutional ownership tend to smooth their dividends less. Well-established firms, cash cows, and firms with low growth prospects, by contrast, tend to smooth dividends more. Leary and Michaely also link these findings to theories of dividend smoothing.
} 
where $i$ indexes countries and $\beta_{\mathrm{FS}}$ measures how the interaction term affects the left-hand-side variables. As outlined in Section III, we expect dividend yields to forecast dividend growth with a negative sign. Hence, if firm size is associated with less strong dividend predictability, we would expect $\beta_{\mathrm{FS}, d}^{(h)}$ to be positive.

We show the results in Table $4 .{ }^{17}$ Panel A shows the results in which we use the average firm size as the measure of the size of the typical firm in the country (interaction coefficient labeled $\beta_{\mathrm{FS}}$ ), and Panel B shows the results from using the $90 \%$ quantile of the firm-size distribution within a country (interaction coefficient labeled $\beta_{\mathrm{Q} 90}$ ). Regardless of the measure of the typical size of a firm in a country, the results are clear-cut: Firm size has a positive impact on the predictive coefficient; that is, the larger is the typical firm in a country, the closer to 0 is the predictive impact of dividend yields on future dividend-growth rates (i.e., the less strong is dividend predictability). We also see that the interaction term is statistically significant for forecast horizons of up to $h=12$ using NeweyWest (1987) based $t$-statistics.

In contrast to the clear effect of firm size on dividend predictability, the effect of firm size on return predictability is less clear. There are two possible reasons

TABLE 4

Predictive Panel Regressions with Firm-Size Measures

Table 4 shows results for panel predictive regressions of future dividend growth or total returns (over forecast horizon $h=4,8,12,16$ quarters) on lagged (log) dividend yields and an interaction term of (log) dividend yields and average firm size (upper part), or the $90 \%$ quantile of the cross-sectional firm-size distribution (lower part):

$$
\begin{aligned}
\Delta d_{i, t+h} & =\alpha_{i, d}^{(h)}+\beta_{d}^{(h)}\left(d_{i, t}-p_{i, t}\right)+\beta_{\mathrm{FS}, d}^{(h)}\left(d_{i, t}-p_{i, t}\right) \mathrm{FS}_{i, t}+\varepsilon_{i, t+h}^{(h)}, \\
r_{i, t+h} & =\alpha_{i, r}^{(h)}+\beta_{r}^{(h)}\left(d_{i, t}-p_{i, t}\right)+\beta_{\mathrm{FS}, r}^{(h)}\left(d_{i, t}-p_{i, t}\right) \mathrm{FS}_{i, t}+\varepsilon_{i, t+h}^{(h)} .
\end{aligned}
$$

The $t$-statistics are based on Newey-West (1987) $\left(t^{\mathrm{NW}}\right)$ or bootstrapped standard errors $\left(t^{\mathrm{BS}}\right)$, and the panel regressions employ fixed effects to focus on time-series effects within countries.

\begin{tabular}{|c|c|c|c|c|c|c|c|c|c|}
\hline \multicolumn{5}{|c|}{ Dividend Growth } & \multicolumn{5}{|c|}{ Total Returns } \\
\hline$h$ & 4 & 8 & 12 & 16 & $h$ & 4 & 8 & 12 & 16 \\
\hline \multicolumn{10}{|c|}{ Panel A. Interaction of Dividend Yield with Average Firm Size } \\
\hline$\beta_{d}$ & -16.27 & -21.19 & -23.21 & -25.95 & $\beta_{r}$ & 11.68 & 25.68 & 33.46 & 37.79 \\
\hline$t^{\mathrm{NW}}$ & $\begin{array}{l}{[-4.49]} \\
{[-3.75]}\end{array}$ & $\begin{array}{l}{[-4.02]} \\
{[-2.93]}\end{array}$ & $\begin{array}{l}{[-3.76]} \\
{[-2.54]}\end{array}$ & $\begin{array}{l}{[-3.62]} \\
{[-2.53]}\end{array}$ & $t^{\mathrm{NW}}$ & $\begin{array}{l}{[4.33]} \\
{[3.92]}\end{array}$ & $\begin{array}{l}{[5.98]} \\
{[4.81]}\end{array}$ & $\begin{array}{l}{[5.69]} \\
{[4.31]}\end{array}$ & $\begin{array}{l}{[5.18]} \\
{[3.93]}\end{array}$ \\
\hline$\beta_{\mathrm{FS}}$ & 3.56 & 5.66 & 5.13 & 3.92 & $\beta_{\mathrm{FS}}$ & -3.01 & -3.37 & -4.11 & -7.58 \\
\hline$t^{\mathrm{NW}}$ & [2.13] & [2.53] & [1.99] & [1.48] & $t^{N W}$ & {$[-2.64]$} & {$[-1.89]$} & {$[-1.79]$} & {$[-2.73]$} \\
\hline$t^{\mathrm{BS}}$ & {$[1.97]$} & {$[1.86]$} & {$[1.36]$} & {$[0.97]$} & $t^{\mathrm{BS}}$ & {$[-2.34]$} & {$[-1.47]$} & {$[-1.25]$} & {$[-1.91]$} \\
\hline $\bar{R}^{2}$ & 0.16 & 0.19 & 0.15 & 0.12 & $\bar{R}^{2}$ & 0.08 & 0.14 & 0.17 & 0.22 \\
\hline \multicolumn{10}{|c|}{ Panel B. Interaction of Dividend Yield with $90 \%$ Quantile of Firm-Size Distribution } \\
\hline$\beta_{d}$ & -16.73 & -23.29 & -24.92 & -28.25 & $\beta_{r}$ & 15.63 & 31.19 & 40.49 & 46.36 \\
\hline$t_{\mathrm{BS}}^{\mathrm{NW}}$ & {$[-5.15]$} & {$[-4.93]$} & {$[-4.60]$} & {$[-4.27]$} & $t^{\mathrm{NW}}$ & [6.46] & [7.82] & [7.03] & [6.43] \\
\hline$t^{\mathrm{BS}}$ & {$[-4.15]$} & {$[-3.65]$} & {$[-3.25]$} & {$[-3.01]$} & & {$[5.87]$} & [6.29] & {$[5.57]$} & [5.09] \\
\hline$\beta_{Q 90}$ & 3.61 & 4.33 & 3.68 & 1.88 & $\beta_{Q 90}$ & -1.46 & -0.59 & -0.40 & -3.47 \\
\hline$t_{\mathrm{RS}}^{\mathrm{NW}}$ & [2.18] & [2.19] & [1.83] & {$[0.78]$} & ${ }_{t}^{\mathrm{NW}}$ & {$[-1.33]$} & {$[-0.31]$} & {$[-0.14]$} & {$[-1.03]$} \\
\hline$t^{\mathrm{BS}}$ & [1.93] & {$[1.57]$} & {$[1.12]$} & {$[0.46]$} & $t^{\mathrm{BS}}$ & {$[-1.17]$} & {$[-0.25]$} & {$[-0.11]$} & {$[-0.77]$} \\
\hline $\bar{R}^{2}$ & 0.15 & 0.16 & 0.12 & 0.09 & $\bar{R}^{2}$ & 0.07 & 0.13 & 0.16 & 0.20 \\
\hline
\end{tabular}

Dividend Growth

${ }^{17} \mathrm{We}$ also performed panel predictive regressions with the interaction variable included as an additional regressor, with no material changes to the conclusions. These results together with results from the panel predictive regressions without interaction terms can be obtained from the authors. 
for this. First, Chen et al. (2012) show theoretically and by using simulations that the effect of dividend smoothing on return predictability is unclear (in contrast to the negative effect of dividend smoothing on dividend predictability), making it difficult to establish a clear link between firm size and return predictability. Second, and given our findings from Tables 2 and 3, as returns are predictable in both large and small countries, it is also not too surprising that we do not find a clear effect of firm size on return predictability.

\section{B. Volatility and Dividend Predictability}

The next question we deal with is whether dividends are more predictable in markets populated by firms whose volatility of fundamentals and returns is high. These tests again draw on the finding documented by Leary and Michaely (2011) that young and less stable firms tend to smooth their dividends less. If dividend smoothing matters for the extent to which dividend growth is predictable by the dividend yield, as argued in Chen et al. (2012), one would expect to find stronger evidence for dividend predictability in markets dominated by firms with more volatile fundamentals and returns.

We use three measures of volatility: raw dividend volatility, idiosyncratic dividend volatility, and idiosyncratic return volatility. Raw dividend volatility is computed as the sum of absolute quarterly log changes of dividends over the last year, while idiosyncratic dividend volatility is calculated from a regression of each country's log dividend growth on the aggregate, global dividend-growth rate, and then summing the absolute residuals over the last 4 quarters. Idiosyncratic return volatility is calculated from a regression of each country's total market return on the aggregate, global stock return, and then summing the absolute residuals over the last 4 quarters. We include idiosyncratic return volatility here to capture the general information environment of a market and since it has been shown to be related to the volatility of fundamental cash flows (see Irvine and Pontiff (2009) on the latter point).

In Table 5, we present the results from predictive panel regressions (for returns and dividends) in which we interact dividend yields with one of the measures of dividend volatility or return volatility, respectively. If dividend-growth predictability is stronger in equity markets populated by firms with higher volatility of fundamentals and equity returns, we would expect a negative sign with the interaction term, as this implies an even stronger predictive effect of the dividend yield for future dividend growth in countries with higher volatility.

Our results clearly indicate that dividend-growth rates are more predictable by dividend yields in countries where the volatility of firms' returns and cash flows is higher. For returns, on the other hand, there is generally no relation between volatility and return predictability. Hence, both the typical size of a firm in a country (Table 4) and volatility (Table 5) affect dividend predictability, but not return predictability.

To shed more light on the relative importance of dividend versus return volatility for dividend predictability, we regress Cochrane's (2008) long-run dividend betas (from Table 2) on one of our measures of dividend and return volatility and average firm size. As we have one long-run beta per country, these are 
TABLE 5

Predictive Panel Regressions and Volatility Measures

The setup of Table 5 is similar to that of Table 4, but here we interact with measures of country volatility: i) lagged dividend volatility (sum of absolute quarterly log changes of dividends over the last year) in Panel A, ii) lagged idiosyncratic dividend volatility in Panel B, and iii) idiosyncratic return volatility in Panel C. Idiosyncratic volatilities are obtained by first regressing each country's (log) dividend growth (or total market return) on the aggregate, global dividend-growth rate (or return), and then summing the absolute residuals over the last 4 quarters.

Dividend Growth

\begin{tabular}{|c|c|c|c|c|c|c|c|c|c|}
\hline \multicolumn{5}{|c|}{ Dividend Growth } & \multicolumn{5}{|c|}{ Total Returns } \\
\hline$h$ & 4 & 8 & 12 & 16 & $h$ & 4 & 8 & 12 & 16 \\
\hline \multicolumn{10}{|c|}{ Panel A. Interaction of Dividend Yield with Dividend Volatility } \\
\hline$\beta_{d}$ & -26.22 & -35.25 & -35.33 & -34.61 & $\beta_{r}$ & 16.29 & 31.17 & 41.60 & 53.88 \\
\hline$t^{\mathrm{NW}}$ & {$[-7.76]$} & {$[-7.09]$} & {$[-6.43]$} & {$[-5.58]$} & $t^{N W}$ & {$[7.55]$} & {$[8.28]$} & [8.29] & {$[8.97]$} \\
\hline$t^{\mathrm{BS}}$ & {$[-7.66]$} & {$[-6.32]$} & {$[-5.34]$} & {$[-4.53]$} & $t^{\mathrm{BS}}$ & {$[7.07]$} & {$[8.12]$} & {$[8.15]$} & {$[8.74]$} \\
\hline$\beta_{\mathrm{VOL}}$ & -9.08 & -33.08 & -17.91 & -22.14 & $\beta$ VOL & 0.26 & -16.04 & -14.43 & -20.40 \\
\hline$t^{\mathrm{NW}}$ & {$[-1.38]$} & {$[-2.42]$} & {$[-3.13]$} & {$[-3.98]$} & $t^{\mathrm{NW}}$ & {$[0.05]$} & {$[-1.84]$} & {$[-1.56]$} & {$[-2.81]$} \\
\hline$t^{\mathrm{BS}}$ & {$[-1.56]$} & {$[-2.73]$} & {$[-2.18]$} & {$[-2.88]$} & $t^{\mathrm{BS}}$ & {$[0.05]$} & {$[-1.99]$} & {$[-1.55]$} & {$[-2.15]$} \\
\hline $\bar{R}^{2}$ & 0.16 & 0.21 & 0.15 & 0.13 & $\bar{R}^{2}$ & 0.06 & 0.11 & 0.15 & 0.20 \\
\hline
\end{tabular}

Panel B. Interaction of Dividend Yield with Idiosyncratic Dividend Volatility

$\begin{array}{lllllllllr}\beta_{d} & -25.03 & -33.94 & -34.33 & -33.51 & \beta_{r} & 15.91 & 31.29 & 42.07 & 54.63 \\ t^{\mathrm{NW}} & {[-7.84]} & {[-6.86]} & {[-6.10]} & {[-5.30]} & t^{\mathrm{NW}} & {[7.33]} & {[8.55]} & {[8.38]} & {[9.22]} \\ t^{\mathrm{BS}} & {[-7.58]} & {[-6.32]} & {[-5.64]} & {[-4.34]} & t^{\mathrm{BS}} & {[6.82]} & {[7.96]} & {[7.69]} & {[8.69]} \\ \beta \mathrm{VOL} & -16.72 & -42.4 & -23.74 & -29.81 & \beta \mathrm{VOL} & 0.89 & -19.71 & -17.96 & -25.62 \\ t^{\mathrm{NW}} & {[-1.45]} & {[-2.24]} & {[-3.43]} & {[-4.09]} & t^{\mathrm{NW}} & {[0.14]} & {[-1.56]} & {[-1.63]} & {[-2.60]} \\ t^{\mathrm{BS}} & {[-1.65]} & {[-2.70]} & {[-2.31]} & {[-3.19]} & t^{\mathrm{BS}} & {[0.15]} & {[-1.89]} & {[-1.55]} & {[-2.14]} \\ \bar{R}^{2} & 0.17 & 0.22 & 0.15 & 0.14 & \bar{R}^{2} & 0.06 & 0.11 & 0.15 & 0.20\end{array}$

Panel C. Interaction of Dividend Yield with Idiosyncratic Return Volatility

\begin{tabular}{lllllllllr}
\hline$\beta_{d}$ & -21.17 & -29.92 & -30.76 & -32.71 & $\beta_{r}$ & 16.92 & 31.37 & 43.16 & 53.46 \\
$t^{\mathrm{NW}}$ & {$[-7.68]$} & {$[-6.42]$} & {$[-5.74]$} & {$[-5.17]$} & $t^{\mathrm{NW}}$ & {$[8.20]$} & {$[8.25]$} & {$[8.13]$} & {$[8.34]$} \\
$t^{\mathrm{BS}}$ & {$[-6.78]$} & {$[-5.73]$} & {$[-4.95]$} & {$[-4.42]$} & $t^{\mathrm{BS}}$ & {$[7.44]$} & {$[7.77]$} & {$[7.92]$} & {$[8.13]$} \\
$\beta$ BOL & -47.26 & -68.13 & -37.24 & -30.30 & $\beta \mathrm{VOL}$ & -3.46 & -23.50 & -37.21 & -29.24 \\
$t^{\mathrm{NW}}$ & {$[-2.44]$} & {$[-2.13]$} & {$[-2.03]$} & {$[-1.70]$} & $t^{\mathrm{NW}}$ & {$[-0.39]$} & {$[-1.37]$} & {$[-2.24]$} & {$[-1.66]$} \\
$t^{\mathrm{BS}}$ & {$[-2.51]$} & {$[-2.12]$} & {$[-1.67]$} & {$[-1.36]$} & $t^{\mathrm{BS}}$ & {$[-0.46]$} & {$[-1.40]$} & {$[-2.00]$} & {$[-1.45]$} \\
$\bar{R}^{2}$ & 0.17 & 0.19 & 0.13 & 0.11 & $\bar{R}^{2}$ & 0.06 & 0.11 & 0.15 & 0.19 \\
\hline
\end{tabular}

cross-sectional regressions. We find that in (unreported) regressions, all three measures of volatility are significant even when controlling for average firm size; but, importantly, when including both idiosyncratic return volatility and one of the two dividend volatility measures in the regression, dividend volatility always drives out return volatility. Hence, based on this admittedly simple test, dividend volatility seems to be more important than return volatility in explaining the crosscountry patterns.

\section{Firm Characteristics and Smoothing}

We have shown in Section III that dividends are more predictable in smaller equity markets. We have also shown in Section IV that dividends are less smoothed in smaller markets. In addition, we have shown that dividends are more predictable in countries where the typical firm is small and uncertainty is high. These are exactly the characteristics of firms that tend to smooth their dividends less, as shown empirically by Leary and Michaely (2011) for U.S. firms.

Now we close the circle and deal with the question of whether dividends are more smoothed in those countries where the typical firm is small and volatility is large. To do so, we calculate the smoothing parameter $S_{i}=\sigma_{i}\left(\Delta d_{i}\right) / \sigma_{i}\left(\Delta e_{i}\right)$ for 
each country $i$ and regress the smoothing parameter on the typical size of the firm in a country in a simple cross-sectional regression (with White (1980) standard errors, which are robust to heteroskedasticity). We employ average firm size here, but using the $90 \%$ quantile measure yields very similar results. We also run the same regression with volatility instead of average firm size. We employ idiosyncratic return volatility as our proxy for volatility here to maximize the distance between our explanatory variable and the dependent variable, which clearly depends on (raw) dividend volatility itself.

The results are shown in Table 6. We find that dividend smoothing is more pronounced in countries with larger typical firm size and lower idiosyncratic return volatility. The fact that we find less dividend predictability by the dividend yield in countries populated by large and stable firms, and that smoothing is related to dividend predictability, extends and lends further support to the results in Chen et al. (2012) and Leary and Michaely (2011).

\section{TABLE 6}

Dividend Smoothing, Firm Size, and Volatility

\begin{tabular}{|c|c|c|c|}
\hline & 1 & 2 & 3 \\
\hline Constant & $\begin{array}{c}-0.42 \\
{[-3.16]}\end{array}$ & $\begin{array}{c}-0.78 \\
{[-5.15]}\end{array}$ & $\begin{array}{c}-0.88 \\
{[-6.07]}\end{array}$ \\
\hline Average firm size & $\begin{array}{c}-0.15 \\
{[-2.14]}\end{array}$ & - & $\begin{array}{l}-0.12 \\
{[-1.76]}\end{array}$ \\
\hline Idiosyncratic return volatility & - & $\begin{array}{c}5.25 \\
{[4.05]}\end{array}$ & $\begin{array}{c}4.39 \\
{[2.99]}\end{array}$ \\
\hline $\bar{R}^{2}$ & 0.10 & 0.28 & 0.33 \\
\hline
\end{tabular}

\section{Robustness}

We tested whether our results are robust along several different dimensions. In this section, we briefly indicate what we did as well as the main findings.

First, we took special care in evaluating the robustness of our results with respect to special kinds of countries. For instance, we excluded the United Kingdom and the United States from the EW and VW portfolios and ran the regressions in Table 3 in order to see whether these two very large common law countries drive our results. We found that even after excluding the United Kingdom and the United States, there is still more dividend predictability in the EW portfolio. ${ }^{18}$

Second, we checked whether our results are driven by recently added small emerging markets. They are not. To verify this, we conducted our time-series regressions using a data set consisting exclusively of countries for which we have

\footnotetext{
${ }^{18}$ Moreover, results for the global EW and VW portfolios above were based on returns in local currencies. In a previous version of the paper, we converted all returns to U.S. dollars before forming the EW and VW portfolios. The results were very similar; that is, the results are robust against using returns either in local currencies or U.S. dollars.
} 
more than 15 years of data. The main result from these exercises is that dividends are more predictable in the EW portfolio than in the VW portfolio, but the results are naturally somewhat less pronounced than the ones reported in the paper itself, as a result of the reduction in the number of countries included in these tests. We also took a second approach to this issue: Instead of excluding countries for which we have only less than 15 years of data, we investigate what happens if we run the regression over a period where we have data for basically all countries. For instance, if we start the analysis in 1995, we have data for all 50 countries except Bulgaria, South Korea, Rumania, and Slovenia. Of course, when using data from 1995 onward, we have many fewer observations if running our regressions for the EW and VW portfolios, so we run a panel regression instead. In this panel regression, we add an interaction term between the size of the equity market in the country and the dividend yield. We find the same results as above, that is, more predictability in small markets, although the results are not as strong as those in the paper itself, probably due to the short sample period.

We have focused on regression results in this paper. In order to evaluate the economic importance of our findings more directly, and to derive the results using methods other than univariate time-series regressions, we sorted countries into five portfolios based on their (lagged) dividend yields (see Cochrane (2011) for a discussion of how results from portfolio sorts relate to results from predictive regressions). In these (unreported) tests, we found that there is also economically significant cross-sectional predictive content of the dividend yield for dividend growth across countries.

\section{Conclusion}

The common finding in the literature is that dividend yields do not predict dividend-growth rates in the standard predictive regression setting based on U.S. aggregate postwar data. We show that the picture painted by U.S. data changes quite a bit when using aggregate data from other countries worldwide. Indeed, we show that dividend-growth predictability accounts for a sizable fraction of dividend-yield variability in the vast majority of countries outside the United States. Dividend-growth predictability by the dividend yield is most pronounced in countries with smaller and medium-sized market capitalization.

To explain these findings, we show that dividends are more predictable in countries where the typical firm is smaller and returns and dividends are more volatile. We also show that dividends are less smooth in such markets. We note that dividend smoothing reduces dividend predictability, because it breaks the link between fluctuations in the dividend yield and future dividends (as shown in Chen et al. (2012)). The extent to which firms in different markets smooth dividends thus emerges as a key mechanism that may explain why the dividend yield does predict dividend growth in the majority of countries worldwide (typically smaller and medium-sized markets) but does not predict dividend growth in some other important countries (typically large markets such as the United States).

Taken together, our findings indicate that the apparent lack of dividend predictability in the United States does not generally extend to other countries. Rather, dividends are in general more predictable in smaller markets and linked to 
firm characteristics in the individual countries. These results suggest that aspects such as cross-country differences in firm characteristics and dividend smoothing also matter for aggregate asset pricing phenomena such as dividend-growth predictability by the dividend yield.

Our main contribution in this paper has been to expand upon the U.S.-based literature that relates dividend-yield fluctuations to dividend-growth rate news. An interesting extension of this research would be an exploration of the predictability of measures of total cash flows (i.e., including share repurchases) instead of dividends only. Using U.S. data, Chen et al. (2012) show that expectations of future cash-flow fluctuations, as opposed to dividend-growth fluctuations that might be influenced by dividend smoothing, account for a larger fraction of dividend-yield fluctuations than expectations of dividend-growth rate fluctuations. Hence, it would be interesting to see whether the findings of Chen et al. extend to an international setting with a rich cross-country dimension. To do so, however, one needs international time-series data on share repurchases in many countries spanning sufficiently long periods of time. Collecting such data and testing whether alternative measures of cash-flow news perhaps account for even larger fractions of dividend-yield fluctuations than reported in this paper may be an interesting avenue for future research.

\section{References}

Ang, A. "Characterizing the Ability of Dividend Yields to Predict Future Dividends in Log-Linear Present Value Models." Working Paper, Columbia University (2002).

Ang, A., and G. Bekaert. "Stock Return Predictability: Is It There?" Review of Financial Studies, 20 (2007), 651-707.

Bansal, R., and A. Yaron. "Risks for the Long Run: A Potential Resolution of Asset Pricing Puzzles." Journal of Finance, 59 (2004), 1481-1509.

Campbell, J. Y. “A Variance Decomposition for Stock Returns.” Economic Journal, 101 (1991), 157-179.

Campbell, J. Y. "Consumption-Based Asset Pricing." In Handbook of the Economics of Finance, G. Constantinides, M. Harris, and R. Stulz, eds. Amsterdam: North Holland (2003), 803-887.

Campbell, J. Y., and J. Ammer. "What Moves the Stock and Bond Markets? A Variance Decomposition for Long-Term Asset Returns." Journal of Finance, 48 (1993), 3-37.

Campbell, J. Y., and J. H. Cochrane. "By Force of Habit: A Consumption-Based Explanation of Aggregate Stock Market Behavior.” Journal of Political Economy, 107 (1999), 205-251.

Campbell, J. Y., and R. J. Shiller. "The Dividend-Price Ratio and Expectations of Future Dividends and Discount Factors." Review of Financial Studies, 1 (1988a), 195-228.

Campbell, J. Y., and R. J. Shiller. "Stock Prices, Earnings and Expected Dividends." Journal of Finance, 43 (1988b), 661-676.

Campbell, J. Y., and S. B. Thompson. "Predicting the Equity Premium Out of Sample: Can Anything Beat the Historical Average?" Review of Financial Studies, 21 (2008), 1509-1531.

Chen, L. "On the Reversal of Return and Dividend Growth Predictability: A Tale of Two Periods." Journal of Financial Economics, 92 (2009), 128-151.

Chen, L.; Z. Da; and R. Priestley. "Dividend Smoothing and Predictability." Management Science, 58 (2012), 1834-1855.

Chen, L., and X. Zhao. "Return Decomposition." Review of Financial Studies, 22 (2009), 5213-5249.

Cochrane, J. H. "Volatility Tests and Efficient Markets: Review Essay." Journal of Monetary Economics, 27 (1991), 463-485.

Cochrane, J. H. "Explaining the Variance of Price-Dividend Ratios." Review of Financial Studies, 5 (1992), 243-280.

Cochrane, J. H. "The Dog That Did Not Bark: A Defense of Return Predictability." Review of Financial Studies, 21 (2008), 1533-1575.

Cochrane, J. H. “Discount Rates.” Journal of Finance, 66 (2011), 1047-1108. 
DeAngelo, H.; L. DeAngelo; and D. J. Skinner. "Are Dividends Disappearing? Dividend Concentration and the Consolidation of Earnings." Journal of Financial Economics, 72 (2004), 425-456.

Engsted, T., and T. Q. Pedersen. "The Dividend-Price Ratio Does Predict Dividend Growth: International Evidence." Journal of Empirical Finance, 17 (2010), 585-605.

Goyal, A., and I. Welch. "Predicting the Equity Premium with Dividend Ratios." Management Science, 49 (2003), 639-654.

Hodrick, R. J. "Dividend Yields and Expected Stock Returns: Alternative Procedures for Inference and Measurement." Review of Financial Studies, 5 (1992), 357-386.

Irvine, P. J., and J. Pontiff. "Idiosyncratic Return Volatility, Cash Flows, and Product Market Competition." Review of Financial Studies, 22 (2009), 1149-1177.

Koijen, R., and J. H. van Binsbergen. "Predictive Regressions: A Present-Value Approach." Journal of Finance, 65 (2010), 1439-1471.

Larrain, B., and M. Yogo. "Does Firm Value Move Too Much to Be Justified by Subsequent Changes in Cash Flow?" Journal of Financial Economics, 87 (2008), 200-226.

Leary, M. T., and R. Michaely. "Determinants of Dividend Smoothing: Empirical Evidence." Review of Financial Studies, 24 (2011), 3179-3249.

Lettau, M., and S. C. Ludvigson. "Expected Returns and Expected Dividend Growth." Journal of Financial Economics, 76 (2005), 583-626.

Lewellen, J. "Predicting Returns with Financial Ratios." Journal of Financial Economics, 74 (2004), 209-235.

Lintner, J. "Distribution of Incomes of Corporations among Dividends, Retained Earnings and Taxes." American Economic Review, 46 (1956), 97-113.

Newey, W. K., and K. D. West. "A Simple, Positive Semi-Definite, Heteroskedasticity and Autocorrelation Consistent Covariance Matrix." Econometrica, 55 (1987), 703-708.

Stambaugh, R. F. "Predictive Regressions." Journal of Financial Economics, 54 (1999), 375-421.

Vuolteenaho, T. "What Drives Firm-Level Stock Returns?" Journal of Finance, 57 (2002), 233-264.

White, H. "A Heteroskedasticity-Consistent Covariance Matrix Estimator and a Direct Test for Heteroskedasticity." Econometrica, 48 (1980), 817-838. 